\title{
Platonic Triangles and Fundamental Triads as the Basic Elements of the World
}

\author{
By Mark Burgin*
}

Plato introduced and explored many influential ideas. However, later researchers and thinkers did not properly interpreted and correctly understood all of his ideas. In this paper, we evoke one of the clusters of such ideas, namely, Plato's ontology based on Platonic bodies and elementary triangles. The goal is to find a relevant scientific interpretation of this idea. Based on the scientific picture of the world, we show that the whole Plato ontology has its relevant counterpart in contemporary science and mathematics.

\section{Introduction}

Plato (427-347 B.C.E.) is one of the greatest philosophers of all times and all nations. Some of his ideas had a formative impact on a diversity of philosophers and scientists, who worked with these ideas discovering new realms in the philosophical milieu. These ideas have come to our time as the greatest achievements of the human mind and creativity finding their reflection in contemporary science. The World of Ideas or Forms is an example of such a groundbreaking idea, the scientific counterpart of which is explicated in. ${ }^{1}$ This explication cracks the problem, the solution of which escaped the best thinkers, who tried to comprehend how the world in which people live is organized and functions.

However, there were other ides of Plato, which have attracted much less attention from other thinkers and have been treated as auxiliary and negligible. Triangles as the basic elements, from which everything in the world is created, are an example of such a forgotten idea. In the light of modern physics, which studies the most fundamental regularities of the universe, this idea looks ungrounded and ridiculous. As Brown writes, "The speculative details of Plato's "account of the universe" are not very satisfactory from the modern point of view ...." .2

In spite of this attitude, we explore Plato's description of the physical world in this paper with goal of finding, if possible, a scientific counterpart of Platonic triangles. The reason for such an exploration is importance of the problem, which was posed in the Presocratic philosophy and emerged even before in different

\footnotetext{
${ }^{*}$ Visiting Scholar, University of California, Los Angeles, USA.

1. Mark Burgin, "Ideas of Plato in the context of contemporary science and mathematics," Athens Journal of Humanities and Arts 4, no. 3 (July 2017).

2. K. Brown, Platonic Solids and Plato's Theory of Everything. Retrieved from goo.gl/3ejk62.
} 
cultures and teachings. For millennia, the problem "What is the world made of?" puzzled the best thinkers in different nations and civilizations. At first, philosophers tried to solve it. Then it was inherited by physics in its search for elementary particles of the physical universe.

The results obtained in this paper show that although the model of the physical universe created by contemporary science is basically different from Platonic cosmology, there is a formative conceptual correspondence (homomorphism) between the physical microcosm and the Cosmos of Plato.

\section{Platonic Triangles as the Basic Elements of the Physical World}

In his dialogue Timaeus, after discussing the "works of intellect (nous)" related to the World of Ideas, Plato describes the "works of necessity" associated with the material reality. ${ }^{3}$ To do this, Plato explains his cosmology explains his ideas about the structure of the physical world - the Cosmos contrasting it to the World of Ideas.

According to Plato, the Cosmos is a reflection (image or shadow) of the World of Ideas and is comprehended by opinion and perception by senses. The Cosmos is becoming and everything in it "comes to be and passes away, but never really is." It has bodily form being visible and tangible. This implies that its constituents must include fire and earth. To create the multiplicity of material things, fire and earth must be combined demanding, at least, one other ingredient that serves to combine them. Treating fire and earth as substances (bodies), Plato comes to the conclusion that there are two intermediates - air and water - to combine them. This gives us four basic elements of the world: fire, earth, air and water. The four elements are "the most excellent four bodies that can come into being" (Timaeus, 53e). Plato also explicates proportionality in these elements:

as fire is to air, air is to water as air is to water, water is to earth.

Introducing an extremely innovative idea of the World of Ideas, Plato build the ontology of the physical world using best achievements of his predecessors. He took the idea that fire, earth, air and water as the basic elements of the world from works of Presocratic philosophers ${ }^{4}$ developing it much further.

Indeed, with the emergence of Western philosophy, which is attributed to Thales (ca. 624-545 B.C.E.), philosophers started to ponder and discuss the

3. Plato, The Collected Dialogues of Plato, ed. Edith Hamilton, Huntington Cairns, and trans. Lane Cooper (Princeton: Princeton University Press, 1961).

4. Daniel W. Graham, The Texts of Early Greek Philosophy: The Complete Fragments and Selected Testimonies of the Major Presocratics. 2 vols. (Cambridge: Cambridge University Press, 2010). 
problem how the world was created and organized. Thus, Thales held water to be a component of all things. Xenophanes (ca. 570-478 B.C.E.) posited that all things came to be from earth. Heraclitus of Ephesus (ca. 535-475) considered fire as the most fundamental element writing "All things are an interchange for fire, and fire for all things, just like goods for gold and gold for goods." Anaximenes (ca. 546528/5 B.C.E.) believed air underlying all other things. Empedocles of Agrigentum (ca. 492-432 B.C.E.) combined all these ideas suggesting that everything in the world was created from fire, earth, air and water. Contrary to these approaches, Anaximander (ca. 610-545 B.C.E.) posited an unknown essence called apeiron (the boundless) as a source for the cosmos.

However, in contrast to other philosophers, Plato did not suppose these elements being really elementary explaining that they come into being from geometrical "molecules" or "primary bodies" of which these elements are composed. Namely, each of four basic elements of the world - fire, earth, air and water - is made up of particles ("primary bodies" or corpuscles), which are regular geometrical solids: a tetrahedron, cube, octahedron and icosahedron. These solids are situated in the empty space, which is "the receptacle of all becoming" (Timaeus, 49a). In this picture, Plato creatively combined the essentialist approach of Thales, Xenophanes, Heraclitus, Anaximenes, Empedocles and many others who put forward some essences (elements) as the foundation of the physical universe (the Cosmos) with atomistic approach of Leucippus of Miletus (ca. $480-420$ B.C.E.) and Democritus from Abdera (460-370 B.C.E.). One more innovation of Plato was the possibility of transmutation of elements. Indeed, Empedocles assumed that although the basic elements as "the roots of all things" could be mixed together in various proportions, the elements themselves were unbreakable, and could never be changed. In contrast, Plato's theory permitted the basic geometrical solids and consequently, the basic elements to transmute and re-combine into different kinds of solids and consequently, different basic elements.

Besides, according to Plato, all basic elements of the physical world are only reflections of the corresponding Forms (Ideas) from the World of Ideas. For instance, the fires people can see are only reflections, in the receptacle, of the Idea (Form) of a Fire. Water in a river or sea is a reflection of the Idea (Form) of Water. This was a new revolutionary idea in philosophy, which waited millennia for its scientific explanation and verification.

Each of the particles (corpuscles) is related to a specific element as the type of the building "bricks" of this element. A particle of fire is a tetrahedron. A particle of earth is a cube. A particle of air is an octahedron. A particle of water is an icosahedron. These geometrical objects are now called Platonic bodies.

Then Plato argues that all bodies "have depth," i.e., are 3-dimensional, and hence are bounded (formed in some sense) by finite surfaces, which in the case of regular geometrical solids are bounded by straight lines. Further reasoning is an example philosophical inference and looks very logical. It goes in the following way. 
Any surface bounded by straight lines is divisible into triangles, while all faces (sides) of Platonic bodies are surface bounded by straight lines. This is how Plato brings his readers (listeners) to Platonic triangles or fundamental triangles as certain geometrical "atoms" (Timaeus, 53c-d). Namely, the four particles are like the molecules of matter, which is built of four elements (Platonic bodies), while the triangles are its atoms forming four particles.

Then Plato continues, any triangle is divisible into right triangles, i.e., it is composed of right triangles. At the same time, an arbitrary right triangle is either isosceles, which has two equal sides (legs) and two $45^{\circ}$ angles, or scalene, in which all sides are different. Therefore, it is possible to build all bodies using isosceles and scalene right triangles, which are considered fundamental and elementary. The fundamental triangles are constructed in such a way as to explain how the transmutation of elements is possible.

Discussing triangles, Plato explains that there is only one kind of isosceles right triangles, namely, the ones that have angles $45^{\circ}, 45^{\circ}$ and $90^{\circ}$ (Timaeus, 54a1). At the same time, there are "infinitely many" kinds of scalene right triangles. To make his theory more precise, Plato chooses "one as the most excellent," "whose longer side squared is always triple its shorter side" (Timaeus, 54b5-6). In addition, this triangle has one more distinctive property, namely, his "hypotenuse is twice the length of its shorter side" (54d6-7). This implies that the angles of such a triangle are $30^{\circ}, 60^{\circ}$ and $90^{\circ}$.

Faces of Platonic bodies are composed of the Platonic triangles. Each face of a Platonic body is either an equilateral triangle or a square. Equilateral triangles are made of scalene right triangles while squares are formed of isosceles right triangles. Namely, it is possible to build an equilateral triangle using six scalene right triangles, while to compose a square, it is feasible to employ four isosceles right triangles.

As a result, having four sides, a tetrahedron (the particle of fire) comprises 24 scalene right triangles. An octahedron (the particle of air) contains 48 scalene right triangles. An icosahedron (the particle of water) consists of 120 scalene right triangles. Finally, a cube (the particle of earth) embraces 24 isosceles right triangles.

Plato suggested the following schema of transformations (transmutations) of fundamental particles (Platonic bodies) into one another, which is presented in (Timaeus, 56c-57c). Taking into account the difference between scalene and isosceles right triangles, Plato concludes that transformations are possible only among fire, air, and water. It is interesting that all permissible transformation preserve the number of geometrical "atoms" - Platonic triangles and consequently, the surface area of Platonic polyhedral (Platonic bodies), i.e., the law of fundamental triangle conservation is valid in the Platonic Cosmos. As a result, only the following transmutations are possible: 


\section{1 air particle $\leftrightarrow 2$ fire particles}

because the air particle consists of 8 triangles while the fire particle consists of 4 triangles $(2 \cdot 4=8)$.

\section{1 water particle $\leftrightarrow 1$ fire particle plus 2 air particles}

because the water particle consists of 8 triangles while the fire particle consists of 4 triangles and the air particle consists of 8 triangles $(2 \cdot 8+4=20)$.

\section{2 water particles $\leftrightarrow 5$ air particles}

because the water particle consists of 20 triangles while the air particle consists of 8 triangles $(5 \cdot 8=2 \cdot 20)$.

$$
1 \text { water particle } \leftrightarrow 5 \text { fire particles }
$$

because the water particle consists of 20 triangles while the fire particle consists of 4 triangles $(5 \cdot 4=20)$.

\section{1 water particle $\leftrightarrow 3$ fire particle plus 1 air particles}

because the water particle consists of 8 triangles while the fire particle consists of 4 triangles and the air particle consists of 8 triangles $(1 \cdot 8+3 \cdot 4=20)$.

To conclude, it is interesting to comment that in his ontology, Plato ingeniously synthesized essentialist and atomistic approaches of his predecessors introducing his right triangles as ideal Forms of primordial elementary units on the deeper scale than the four basic elements. As it is demonstrated in the next section, this innovation is well correlated with the contemporary scientific description of the world.

\section{Fundamental Triads as the Basic Elements of the World as a Whole}

As we know, triangles are not basic structures either in nature or in mathematics. However, triangles are a kind of triads and it has been discovered and scientifically proved that specific triads are the most fundamental entities in nature, society, technology and mathematics. Consequently, it is possible to consider these triads as a scientific counterpart of Platonic triangles in a similar way as subatomic particles studied in contemporary physics can be treated as a scientific counterpart of atoms of Leucippus and Democritus. These triads are called fundamental triads or named sets. They exist in the World of Structures, which is a scientific counterpart of the World of Ideas, as 
well as in the physical world. Observations that confirm existence of fundamental triads in nature are described later.

It is possible to discern several types of fundamental triads (named sets): basic fundamental triads, bidirectional fundamental triads of two types and cyclic fundamental triads.

In the symbolic representation, a basic fundamental triad (a named set) has the form $\mathbf{X}=(X, f, I)$ in which $X$ is called the support of $\mathbf{X}, I$ is the component of names (or reflector) of $\mathbf{X}$, and $f$ is the naming correspondence (reflection) of $\mathbf{X}$, which is directed from the support $X$ to the component of names (reflector) $I$.

In the graphic representation, the following diagrams describe a fundamental triad:

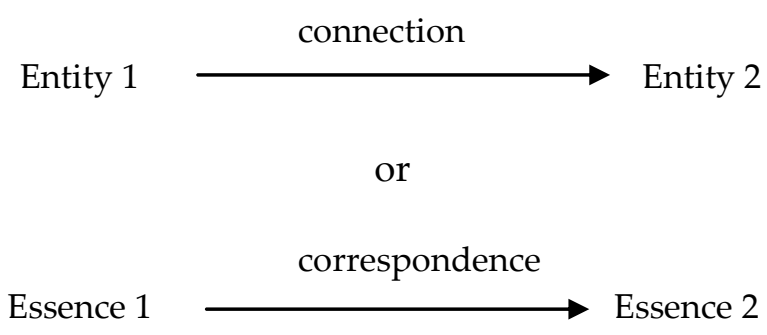

Essence 1

Essence 2

It is interesting that in his dialog Timaeus, Plato comes to the necessity of fundamental triad when he writes, "two things cannot be rightly put together without a third; there must be some bond of union between them." This is an exact description of a fundamental triad: two objects (things) and a connection (bond) between them.

Utilization of two names, named set and fundamental triad, for the same structure envokes different outlooks, perceptions and insights. The term (name) fundamental triad emphasizes intrinsic unity of the three components of the triad and conceptual elementarity of this structure. At the same time, the term (name) named set emphasizes possible decomposability of the triad components and inherent complexity of this structure.

Forming a mathematical foundation for the theory of names and understanding of naming, named sets (fundamental triads) also continue the ancient tradition of thinkers interested in names and naming. ${ }^{5}$ In particular, Plato dedicated his dialog Cratylus to problems of names and naming.

To prove fundamentality of fundamental triad, we show that according to contemporary physics, everything in physical world (the universe) on the structural level is built of fundamental triads. Indeed, two classes of objects form the base of the universe - subatomic (previously, elementary) particles, such as electrons, quarks, protons and neutrons, and physical fields. The latter form the most fundamental concept in physics because quantum physics assumes that

5. Burgin, Theory of Named Sets (New York: Nova Science Publishers, 2011). 
particles are only manifestations of fields, being energetic fragments of fields confined to a definite region.

At first, let us look what a physical field is or more exactly, what physicists think a physical field is. The concept of a field was introduced for a convenient representation of action-at-a-distance forces and was later elevated to the status of a physical entity in its own right. A physical field consists of physical quantities associated to each point of the physical spacetime. Thus, it has the form of the fundamental triad $\mathbf{X}=(V, r, Q)$ where the support $V$ is the physical spacetime, the reflector $Q$ is a set of physical quantities, and the reflection $r$ is a function that associates to each point of $V$ elements from $Q$.

For instance, a magnetic field is an essence produced by moving electric charges (electric currents) that exert a force on other moving charges. The quantum-mechanical spin of a particle also produces magnetic fields and is acted on by them as though it were a current.

In theoretical physics, physical fields are presented (modeled) by mathematical structures, such as scalar, vector and tensor fields on manifolds, which are also fundamental triads having the form $\mathbf{X}=(X, n, D)$ where the support $X$ is a topological (often differentiable) manifold, the reflector $D$ is some set of scalars (real or complex numbers), vectors or tensors and the reflection $n$ is a function defined on $X$ with values in $D$.

For instance, a vector field is a construction in mathematics that associates a vector to every point in the Euclidean space or a manifold. Vector fields are often used in physics to model physical characteristics, such as the speed and direction of a moving fluid throughout space, or the strength and direction of some force, such as the magnetic or gravitational force, as it changes from point to point.

This peculiarity explains why topological fundamental triads, such as fibrations, fiber bundles, sheafs and presheafs are exceptionally useful and popular in theoretical physics. ${ }^{6}$

At the same time, exploring subatomic particles, which were called elementary particles for a while, physicists found that any material particles always interact with one another. Even if we make a mental experiment and take an isolated physical particle, it interacts with (or acts on) itself. Thus, taking a set (or a multiset) $P$ of subatomic particles, we obtain the following named set,

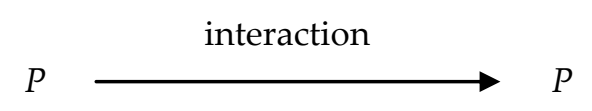

When the set (multiset) $P$ consists of a single particle $p$, we obtain a simpler named set,

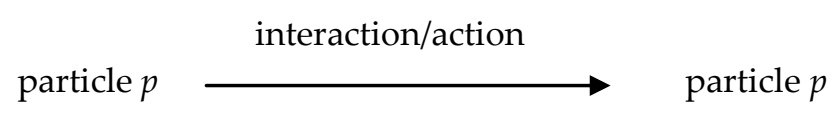

6. Ibid. 
This proves that fundamental triads are the most basic objects in the physical world and everything is built of them because everything is built of subatomic particles and physical fields. However, this is exactly the role that Plato ascribed to his fundamental triangles.

Fundamental triads (named sets), as the most encompassing and fundamental mathematical construction, encompass all generalizations of ordinary sets and provide unified foundations for the whole mathematics. ${ }^{7}$ Many mathematical systems are particular cases of fundamental triads. The most important of such systems are fuzzy sets ${ }^{8}$ and multisets ${ }^{9}$ because they are all natural generalizations of the concept of a set and have many important applications Other systems, such as graphs and hypergraphs, ${ }^{10}$ Boolean valued sets, ${ }^{11}$ topological and fiber bundles, ${ }^{12}$ and many other mathematical structures that are fundamental triads or are constructed from fundamental triads as their construction components. Moreover, any ordinary set is, as a matter of fact, some named set (fundamental triad), and namely, a singlenamed set, that is, such a named set (fundamental triad) in which all elements have the same name. ${ }^{13}$

In addition, it is possible to find many fundamental triads in physics. For instance, according to particle physics, any particle has a corresponding antiparticle, e.g., electron corresponds to positron, while proton corresponds to antiproton. Thus, we have a fundamental triad with particles as its support and antiparticles as its reflector. A particle and its antiparticle have identical mass and spin, but have opposite value for all other non-zero quantum number labels. These labels are electric charge, color charge, flavor, electron number, muon number, tau number, and barion number. Particles and their quantum number labels form another fundamental triads with particles as its support and quantum number labels as its reflector.

7. Burgin, "Theory of Named Sets as a Foundational Basis for Mathematics," in Structures in mathematical theories: reports of the San Sebastian international symposium, September 25-29, 1990, ed. A. Díez, Javier Echeverría, Andoni Ibarra (Editorial Service, University of the Basque Country: Publication Service of the Basque Country, University of the Basque Country, 1990); Burgin, Unified Foundations of Mathematics, Preprint Mathematics LO/0403186 (Cornell University Library, 2004), 39. Electronic edition: arXiv:math/0403186v1 [math.LO]. Retrieved from goo.gl/5b1DCh.

8. Lotfi Zadeh, "Fuzzy Sets," Information and Control 8, no. 3 (1965).

9. Donald Knuth, The Art of Computer Programming, vol. 1: Fundamental Algorithms (Boston/San Francisco/New York: Addison-Wesley, 1997).

10. Claude Berge, Graphs and Hypergraphs (Amsterdam/New York: North Holland P.C., 1973).

11. John Bell, Set Theory: Boolean-Valued Models and Independence Proofs (Oxford: Clarendon Press, 2005).

12. Dale Husemöller, Fibre Bundles (Berlin: Springer Verlag, 1994).

13. Burgin, Theory of Named Sets. 
When we study information and information processes, fundamental triads become extremely important. Each direction in information theory has fundamental concepts and models that are either fundamental triads or systems built of fundamental triads. ${ }^{14}$ For instance, the relation between information and the receiver/recipient is a fundamental triad.

The main argument supporting existence of fundamental triads in the real world is the situation that we can see a variety of fundamental triads around us. When two people are speaking, they form a fundamental triad. Indeed, we have Individual 1 and Individual 2 who are connected by their speech (pronounced words). When two people are speaking by conventional phones, they are connected by wires. When two people are speaking by cell phones, they are connected by radio waves. In all cases, the considered systems form a fundamental triad.

Besides, there are fundamental triads, which people can directly see. Indeed, when it is raining, we see the fundamental triad that consists of a cloud(s) (the support or Entity 1 from Diagram 1), the Earth where we stand (the reflector or Entity 2 from Diagram 1) and flows of water (the correspondence from Diagram 1 or reflection). When we see a lightning, we see another fundamental triad that consists of a cloud(s) (the support or Entity 1 from Diagram 1), the Earth where we stand (the reflector or Entity 2 from Diagram 1) and the lightning (the correspondence from Diagram 1 or reflection). Thus, people can see structures but as Plato wrote about Ideas (eidos), they can comprehend structures only using their intelligence and knowledge.

People often meet fundamental triads in their everyday life and find them in many fundamental structures of the universe. People and their names constitute a fundamental triad/named set. Cars and their owners constitute another fundamental triad. Books and their authors constitute one more fundamental triad. A different example of a fundamental triad is given by the traditional scheme of communication:

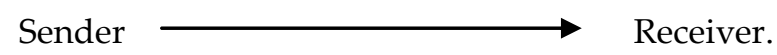

In this case, connection may be one of the following: a channel, communication media, or a message.

All these traits of fundamental triads (named sets) influenced the development of an advanced theory of named sets, which has three parts: an informal theory called the theory of fundamental triads, the mathematical theory of named sets, and the applied theory of named sets. ${ }^{15}$

14. Burgin, Theory of Information: Fundamentality, Diversity and Unification (New York: World Scientific, 2010); Burgin, "Information triads," Philosophical and Sociological Thought 7-8 (1993b). (In Russian and Ukrainian)

15. Burgin, Theory of Named Sets. 
Demonstrating the close conceptual association between Platonic triangles and fundamental triads, we can whether it is possible to find in science fundamental triads associated with two types of Platonic triangles. One of the possible interpretations relates the class of fundamental triads used to represent physical fields and the class of fundamental triads used to represent interacting particles to two classes of triangles.

Another possible interpretation is based on two structurally different classes of fundamental triads - basic and bidirectional fundamental triads. While in basic fundamental triads, the naming correspondence (reflection) goes in one direction (from the support to the component of names), in bidirectional fundamental triads, the naming correspondence (reflection) goes in two opposite directions.

In the symbolic representation, a bidirectional fundamental triad (or a bidirectional named set) of the first type has the form $\mathbf{X}=(X,[f, g] I)$ in which $X$ is called the support of $\mathbf{X}, I$ is the component of names (reflector) of $\mathbf{X}$, and $[f, g]$ is the bidirectional reflection of $\mathbf{X}$.

In the graphic representation, the following diagrams describe a bidirectional fundamental triad:

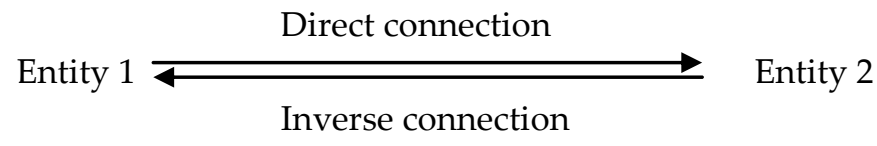

or

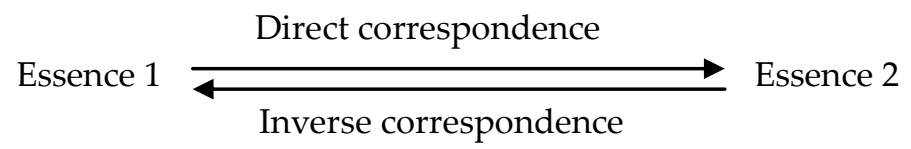

Taking different instantiation of the structure in Diagram (3) [in Diagram (4)], we see that in some cases, direct and inverse connections (correspondences) can physically exist as one object, e.g., one rod or wire. This makes reasonable to consider also bidirectional fundamental triads of the second type, which have a bidirectional fundamental triad connection (correspondence). These triads are presented in Diagrams (5) and (6).

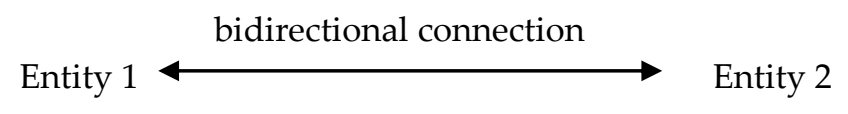

or

bidirectional correspondence 
Similar to the fundamental triad, a bidirectional triad $\mathbf{X}$ consists of three components, that is, $\mathbf{X}=(X, f, I)$.

Any bidirectional triad is the coupling of two fundamental triads. For instance, the bidirectional triad (8) is the coupling of two fundamental triads (9) and (10).

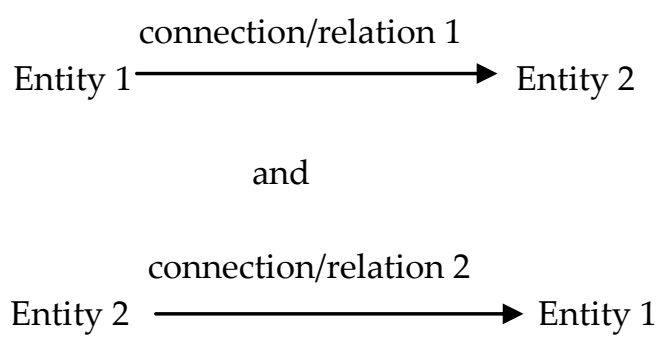

To conclude, it is interesting to mention that conceived in the ancient Greek philosophy the four basic elements of the world fire, earth, air and water also have their scientific counterparts in contemporary physics. Namely, it is possible to interpret basic elements considered by Plato as four fundamental states of matter:

- Fire as plasma;

- Earth as solid bodies (solid matter);

- Water as liquid;

- Air as gas.

In the context of fundamental triads, an interesting peculiarity of Plato's teachings is utilization of various triads. Here are some examples.

The Platonic Triad of higher Forms is often presented as Truth, Beauty, and Goodness or Good. In his dialog Philebus, Plato presents this triad as Beauty, Truth, and Measure (metriotes) or Symmetry (symmetria). A related Platonic Triad is,

(One, Intellect, Soul).

The One gives birth to the Intellect (nous), which in turn, gives birth to the Soul. The Plato's Triad of Soul ( $\psi v \chi \eta \dot{)}):$

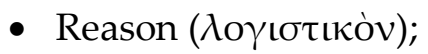

- Spirit $(\theta v \mu о \varepsilon เ \delta \varepsilon ́ s)$;

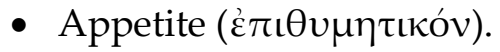

Another famous Platonic triad is a fundamental triad and has the following form,

(World of Ideas, reflection, World of material things). 
The semiotic Platonic triad has the following form,

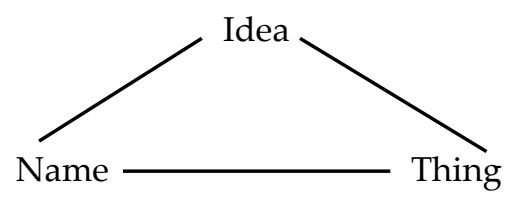

In Republic, using the appetite/spirit/reason structure of the individual soul, Plato introduces the triadic class structure in society: ${ }^{16}$

- The Productive group (caste), which consists of people who produce goods or provide services such as sheppards, carpenters, plumbers, masons, merchants, farmers, ranchers, etc. This group corresponds to the "appetite" part of the soul.

- The Protective group (caste) (Warriors or Guardians), members of which are adventurous, strong and brave. This group corresponds to the "spirit" part of the soul.

- The Governing group (Rulers or Philosopher Kings), members of which are intelligent, rational, self-controlled, in love with wisdom, well suited to make decisions for the community. This little group corresponds to the "reason" part of the soul and are very few.

In Timaeus, Plato defines the triad of parts of the soul within the human body:

- The head contains Reason.

- The top third of the torso contains Spirit.

- The middle third of the torso, down to the navel, contains the appetite.

This triadic tendency in the philosophy of Plato was further developed by subsequent philosophers.

\section{The Triadic Tradition after Plato}

Triad as the basic structure was very popular in works of Neoplatonic philosophers, such as Plotinus, Iamblichus and Proclus (ca. 410-485). The term Neoplatonism was introduced by European philosophers and historians of philosophy in the 19th century as a revival and a new phase in the development of the Platonic tradition.

16. Plato, The Collected Dialogues of Plato. 
Plotinus (ca. 204-270 C.E.), is generally regarded as the founder of Neoplatonism and one of the most influential philosophers in antiquity after Plato and Aristotle. The basic tenet of Plotinus' metaphysics has the form of a triad,

("the One" [or, equivalently, "the Good"], Intellect, Soul)

representing both ultimate ontological realities and explanatory principles, which as Plotinus believed, were recognized by Plato as such, as well as by the entire subsequent Platonic tradition. In addition, Christian thinkers interpreted "the One" as the supreme God.

It is interesting that Neoplatonic philosophers considered the triad (11) not as a static arrangement but as a dynamic formation, in which the One derives Intellect (nous), from which in turn, comes Soul, which forms, orders, and maintains in being the material universe. Plotinus treated the whole process of generation beyond time believing that Nous and Soul are eternal, while time is incorporated in the life of Soul as an active agent in the physical world.

The next prominent Neoplatonist was Iamblichus (ca. 250-325) was the author of the specific type of Neoplatonism, which became dominate the Platonic schools in the 5th and 6th centuries. Iamblichus' ontology was constructed from a large number of triads. In the approach of Iamblichus, Neoplatonism sharpened and multiplied the distinctions between the levels of being assuming that the structure of reality corresponds so exactly to the way in which the mind works that there is a separate real entity corresponding to every distinction that it can make. In the fully developed late Neoplatonic system, the first principle of reality, the ultimate One, was substituted by an indescribable transcendence, alleviated by the presence of the expressions or manifestations of its unifying power and the possibility of return to absolute unification through these manifestations. Below the One, there was a vast structure of triads going down to the physical world. The physical reality was also generated by combining Plotinus's vertical succession of the levels of the triad (Being, Intellect, Soul) with another horizontal triadic structure, existing a timeless dynamic pattern of going in and out.

Later triads proliferated in Western philosophy. The most prominent example is the dialectic triad,

(thesis, antithesis, synthesis)

which is often attributed to the outstanding German philosopher Georg Wilhelm Friedrich Hegel (1770-1831) and called the Hegelian dialectic triad. However, according to some of his biographers, Hegel never used the term himself. According to other biographers, Hegel used this structure only once, attributing the terminology to another German philosopher Immanuel Kant (1724-1804). 
However, according to the majority of sources, the dialectic triad as a basic knowledge acquisition process was explicitly developed by Johann Gottlieb Fichte (1762-1814) in his book Introduction to the Wissenschaftslehre.

At the same time, as Wyatt writes, it was Hegel's contention that the Absolute Truth was a collection of all possible triads in the universe. Mankind could discover truth only if people could recognize every phenomenal triad that existed. ${ }^{17}$

There are various triads in psychology. The most famous one is the structure of the psyche suggested by Sigmund Freud (1856-1939) in psychoanalysis,

$$
\text { (Id, Ego, Super-Ego). }
$$

It is a fundamental triad. Triads also became popular in sociology, linguistics and anthropology. For instance, the prominent sociologist Georg Simmel (1858-1918) asserted that triad is the most basic structure in society. ${ }^{18}$ Later triadic approach in anthropology was developed by under the name cognitive sociology. ${ }^{19}$

Dyadic approach became very popular with the advent of structuralism. ${ }^{20} \mathrm{In}$ the 20th century, structuralism, at first, was used in linguistics and literary studies as a popular tool of analysis. The most prominent representatives of this direction were Ferdinand de Saussure (1857-1913), Louis Hjelmslev (1899-1965), Rasmus Viggo Brendal (1887-1942), Roman Jakobson (1896-1982) and Nikolai Trubetzkoy (1890-1938). Later structuralism came to anthropology and philosophy. The most prominent representatives of this direction were Claude Levi-Strauss (1908-2009), Roland Barthes (1915-1980), Jacques Marie Émile Lacan (1901-1981), Michel Foucault (1926-1984), and Louis Althusser (1918-1990).

Structuralists analyzed world in oppositions, which are an important type of dyads. However, it is important to understand that any dyad and in particular, any opposition is an implicit triad in general and a fundamental triad, in particular. Indeed, a dyad consists of two objects but it becomes a dyad when some relation connects these objects. As result, a dyad is a group of two objects and a connection between them but this is exactly a fundamental triad.

17. Retrieved from goo.gl $/ \mathrm{k} 321 \mathrm{bF}$.

18. Georg Simmel, Soziologie (Sociology) (Leipzig: Duncker \& Humblot, 1908).

19. Karl-Otto Apel, Transformation of Philosophy (London: Routledge \& Kegan Paul, 1980).

20. Jessica Carter, "Structuralism as a Philosophy of Mathematical Practice," Synthese 163, no. 2 (2008); Geoffrey Hellman, Structuralism, in The Oxford Handbook of Philosophy of Mathematics and Logic (New York: Oxford University Press, 2005; Jean Piaget, Structuralism (London: Routledge \& Kegan Paul, 1971). 


\section{Conclusion}

Thus, we have demonstrated that the whole Plato ontology has its relevant counterpart in contemporary science and mathematics. The World of Ideas (Forms) has a relevant representation as the World of Structures. ${ }^{21}$ The four basic elements are mirrored by four fundamental states of matter. The Platonic bodies are exposed (although loosely) by subatomic particles, while fundamental triads play roles similar to the role of Platonic triangles as the basic elements of the world. Moreover, while Plato treated basic triangles as elementary constituents only of the physical world, fundamental triads are indispensable elements of the world as a whole. Indeed, it is also established that fundamental triads are the key structures in human culture, society and sociology, ${ }^{22}$ in the mental world and psychology, ${ }^{23}$ and in cognition and epistemology. ${ }^{24}$

\section{Bibliography}

Apel, Karl-Otto. Transformation of Philosophy. London: Routledge \& Kegan Paul, 1980.

Bell, John. Set Theory: Boolean-Valued Models and Independence Proofs. Oxford: Clarendon Press, 2005.

Berge, Claude. Graphs and Hypergraphs. Amsterdam: North Holland P.C., 1973.

Burgin, Mark. "Ideas of Plato in the context of contemporary science and mathematics." Athens Journal of Humanities and Arts 4, no. 3 (July 2017): 161182.

Theory of Named Sets. New York: Nova Science Publishers, 2011.

—. Theory of Information: Fundamentality, Diversity and Unification. New York: World Scientific, 2010.

- Unified Foundations of Mathematics. Preprint Mathematics LO/0403186. Cornell University Library, 2004. Electronic edition: arXiv:math/0403186v1 [math.LO]. Retrieved from goo.gl/5b1DCh.

21. Burgin, "Ideas of Plato in the context of contemporary science and mathematics.

22. Burgin, "Triad as a Fundamental Structure in Human Culture," Studia Culturologia 2 (1993a); Burgin, Theory of Named Sets.

23. Burgin, "Triad as a Fundamental Psychological Structure," in Proceedings of the Conference Mathematics and Psychology in the Pedagogical System (Odessa: Technical University, 1996), 6-7. (In Russian); Burgin, Theory of Named Sets.

24. Burgin, "Named Sets as a Basic Tool in Epistemology," Epistemologia XVIII (1995); Burgin, "The Structure-Nominative Reconstruction and Intelligibility of Cognition," Epistemologia XV, no. 2 (1992). 
. "Triad as a Fundamental Psychological Structure." In Proceedings of the Conference Mathematics and Psychology in the Pedagogical System. Odessa: Technical University, 1996. (In Russian)

"Named Sets as a Basic Tool in Epistemology." Epistemologia XVIII (1995): 87-110.

_. "Triad as a Fundamental Structure in Human Culture." Studia Culturologia 2 (1993a): 51-63.

_. "Information triads." Philosophical and Sociological Thought 7-8 (1993b): 243-246. (In Russian and Ukrainian)

_. "The Structure-Nominative Reconstruction and Intelligibility of Cognition." Epistemologia XV, no. 2 (1992): 219-238.

"Theory of Named Sets as a Foundational Basis for Mathematics." In Structures in mathematical theories: reports of the San Sebastian international symposium, September 25-29, 1990, edited by A. Díez, Javier Echeverría, Andoni Ibarra, 417-420. Editorial Service, University of the Basque Country: Publication Service of the Basque Country, University of the Basque Country, 1990.

Carter, Jessica. "Structuralism as a Philosophy of Mathematical Practice." Synthese 163, no. 2 (2008): 119-131.

Graham, Daniel W. The Texts of Early Greek Philosophy: The Complete Fragments and Selected Testimonies of the Major Presocratics. 2 vols. Cambridge: Cambridge University Press, 2010.

Hellman, Geoffrey. Structuralism, in The Oxford Handbook of Philosophy of Mathematics and Logic. New York: Oxford University Press, 2005.

Husemöller, Dale. Fibre Bundles. Berlin: Springer Verlag, 1994.

Knuth, Donald. The Art of Computer Programming, vol. 1: Fundamental Algorithms. Boston: Addison-Wesley, 1997.

Piaget, Jean. Structuralism. London: Routledge \& Kegan Paul, 1971.

Plato. The Collected Dialogues of Plato, edited by Edith Hamilton, Huntington Cairns, and translated by Lane Cooper. Princeton: Princeton University Press, 1961.

Simmel, Georg. Soziologie (Sociology). Leipzig: Duncker \& Humblot, 1908.

Zadeh, Lotfi. "Fuzzy Sets." Information and Control 8, no. 3 (1965): 338-353. 